\title{
Circulating Galectin-3 Levels Are Increased in Patients with Ischemic Heart Disease, but Are Not Influenced by Acute Myocardial Infarction
}

\author{
Erlend G. Singsaas ${ }^{a} \quad$ Cord A. Manhenke $^{a} \quad K^{2}$. Mneth Dickstein ${ }^{a, b}$ Stein Orn $^{a, b}$ \\ a Department of Cardiology, Stavanger University Hospital, Stavanger, and b University of Bergen, Bergen, Norway
}

\section{Key Words}

Biomarkers · Galectin-3 - Myocardial infarction - Cardiac magnetic resonance imaging $\cdot$ Left-ventricular remodeling

\begin{abstract}
Objectives: Galectin-3 (Gal-3) is involved in cardiac inflammation and fibrosis, and is in use as a biomarker that indicates increased risk in heart failure. This study examined the relationship between Gal-3 levels and acute and old myocardial infarction (MI) in patients assessed by cardiac magnetic resonance (CMR) imaging. Methods: Group 1 consisted of 38 patients with ST-elevation MI and single-vessel disease treated with primary percutaneous coronary intervention (PCI). Group 2 consisted of 52 patients with prior complicated MI. Twenty-two controls were included. CMR was performed in group 1 at 2 days, 1 week, 2 months and 1 year following PCI and in group 2 at $>4$ years after MI. Results: Median Gal-3 was elevated in patients compared with controls, group 1: 11.93 $\mathrm{ng} / \mathrm{ml}$ (IQR 6.34-17.52, $\mathrm{p}=0.03$ ), group 2: 12.96 (IQR 6.3319.29, $\mathrm{p}=0.03$ ) and controls: 10.16 (IQR 5.59-14.73). Gal-3 levels did not change during acute $\mathrm{Ml}$, and there was no relationship between Gal-3 and infarct size, troponin-T, highsensitivity C-reactive protein, left-ventricular (LV) volumes or LV ejection fraction (LVEF) in group 1. In group 2, Gal-3 cor-
\end{abstract}

related modestly with MI size $(r=0.28, \mathrm{p}<0.05)$, LV end-diastolic volume index $(r=0.40, p<0.01)$, LV end-systolic volume index $(r=0.43, p<0.01)$ and LVEF $(r=-0.39, p<0.01)$. Conclusion: There was no relationship between Gal-3 levels and acute ischemic myocardial injury. A significant, modest relationship between Gal-3 levels, MI size and LV remodeling was only found in patients with old MI.

(c) 2016 S. Karger AG, Basel

\section{Introduction}

Cardiovascular (CV) disease is a major cause of death in the Western world [1]. Despite substantial progress regarding the diagnosis and treatment of these patients, risk stratification remains a challenge. Galectin-3 (Gal-3) has emerged as a promising, novel risk marker in patients with CV disease. Gal-3 is a protein of the lectin family involved in inflammation and fibrosis in various organs, including the heart. It is produced in macrophages, is crucial for macrophage phagocytic function and secreted Gal-3 stimulates the fibroblast production of collagen type I $[2,3]$. Observational studies suggest a role for Gal3 in the development of adverse cardiac remodeling [2, 3]. In a clinical setting, it has been proposed to predict

\section{KARGER}

E-Mail karger@karger.com

www.karger.com/crd
(C) 2016 S. Karger AG, Basel

$0008-6312 / 16 / 1344-0398 \$ 39.50 / 0$ 
heart failure (HF) [4] and all-cause mortality in the general population $[4,5]$ as well as being a marker of an increased risk of $\mathrm{CV}$ events in patients with $\operatorname{HF}[3,6,7]$, especially those with diastolic dysfunction [7-9]. It has also been suggested that Gal-3 may be used to guide medical therapy in patients with $\mathrm{HF}[10,11]$. Its use in clinical practice is prominent, and it has been included in the latest ACC/AHA guideline for the management of HF, with a IIb recommendation for risk stratification of patients with HF [12].

Coronary artery disease (CAD) is a major cause of $\mathrm{HF}$ [13]. Gal-3 has been extensively studied in HF populations, but less is known regarding the relationship between Gal-3 and CAD. There are recent data indicating that Gal-3 predicts long-term CV mortality also in patients with CAD [14]. However, there are unsolved questions on Gal-3 and its relationship to myocardial infarction (MI), especially in the acute phase. The healing of transmural MI includes inflammation and subsequent scarring of the necrotic myocardium. Furthermore, the loss of contractile force might trigger adverse left-ventricular (LV) remodeling, with fibrotic changes not only in the necrotic area but also in the noninfarcted myocardium $[15,16]$. Both these processes, which are pivotal after acute MI, might theoretically cause an upregulation of Gal-3. This assumption is supported by laboratory data [17]. Accordingly, one might expect a relationship between Gal-3, infarct size, infarct healing and LV remodeling in patients with $\mathrm{MI}$, although previous clinical studies on this topic are equivocal [17]. The aim of this study was to study circulating levels of Gal-3 in patients with acute ST-elevation MI (STEMI) and patients with previous complicated MI, and to explore the relationship between Gal-3, MI size and the parameters of LV remodeling assessed by cardiac magnetic resonance (CMR) imaging.

\section{Methods}

\section{Study Population}

In order to address the relationship between Gal-3 and CAD in both acute STEMI and previous complicated MI, 3 populations were included in this study. All patients were required to be without evidence of inflammatory disease or any contraindication to CMR examination including an estimated glomerular filtration rate (eGFR) $<30 \mathrm{ml} / \mathrm{min} / 1.73 \mathrm{~m}^{2}$ (due to the use of gadolinium containing contrast agent during the CMR examination).

Group 1 consisted of 38 patients with first-time, acute STEMI, single-vessel disease, with a large, occluded coronary artery, successfully revascularized by primary percutaneous coronary intervention (PCI) without any residual stenosis.

Gal-3 Levels and Acute MI in Ischemic Heart Disease
Group 2 consisted of 52 patients with a history of complicated MI. They were drawn from a registry of patients included in the Comparison of the Effects of Losartan and Captopril on Mortality and Morbidity in Patients following Acute Myocardial Infarction (OPTIMAAL) trial [18], at a single center (in Stavanger, Norway). The major inclusion criteria in the OPTIMAAL trial were acute MI complicated with HF, LV ejection fraction (LVEF) $<35 \%$, or new Q-wave or anterior-wall acute MI, and the objective was to compare losartan $(50 \mathrm{mg})$ with captopril $(150 \mathrm{mg})$ in such patients. As a consequence, all patients were treated with an angiotensin-converting enzyme inhibitor or an angiotensin receptor blocker. Inclusion in the present study took place, on average, at 4.4 years after MI.

Group 3 served as a reference and consisted of 22 healthy individuals, age- and gender-matched with group 2 . All subjects in this group were without medical therapy, and had no history or symptoms suggestive of CV disease. No CV events occurred in this group during a follow-up spanning 1 year.

This study was approved by the Regional Ethics Committee at the University of Bergen, and all patients gave their informed consent prior to their inclusion. The investigation conformed to the principles outlined in the Declaration of Helsinki.

\section{CMR Imaging Exams}

Patients in group 1 were assessed by late gadolinium-enhanced CMR at 4 different time points after MI: at 2 days, 1 week, 2 months and 1 year after PCI, respectively. The patients in group 2 were examined by CMR once, on average at 4.4 years after the index MI.

CMR was performed with a 1.5-T Philips Intera R 8.3. Functional assessment (LVEF and LV end-diastolic and end-systolic volumes) was performed according to current recommended standards with the use of steady-state, free-precession sequence covering the whole left ventricle with 8-mm-thick, short-axis slices and interslice gaps of $2 \mathrm{~mm}$. Assessment of LV volumes was performed on full, short-axis datasets in a random, blinded fashion, using View Forum ${ }^{\mathrm{TM}}$ software (Philips Medical Systems, Best, The Netherlands). Indices for LV volumes, i.e. LV end-diastolic volume index (LVEDVi) and LV end-systolic volume index (LVESVi), were obtained by correcting for body surface area.

After performing the assessment of LV volumes and LVEF, a gadolinium-based contrast agent, Omniscan ${ }^{\circledR}$, was administered intravenously at a dose of $0.25 \mathrm{mmol} / \mathrm{kg}$ in order to reduce problems with early washout. Late gadolinium-enhanced images were acquired 10-15 min later, using an inversion-recovery-prepared $\mathrm{T}_{1}$-weighted gradient-echo sequence with a typical pixel size of $0.82 \times 0.82 \mathrm{~mm}^{2}$, covering the whole ventricle with short-axis slices of $10 \mathrm{~mm}$ thickness, without interslice gaps. Inversion recovery sequences were performed with individually adapted inversion times of 200-300 ms, aiming to nullify normal myocardium. MI sizes were quantified using these images, and are expressed as percentage of total LV mass.

\section{Laboratory Analysis}

Patients in group 1 had venous blood drawn prior to primary PCI, and at each CMR assessment, i.e. at 2 days, 1 week, 2 months and 1 year following revascularization. Group 2 had venous blood samples taken at the CMR exam at a mean of 4.4 years after the index infarction. To obtain platelet-poor plasma, pyrogen-free blood collection tubes were immediately immersed in melting ice (EDTA-containing tubes) and centrifuged within $20 \mathrm{~min}$ at 
2,500 $\mathrm{g}$ for $20 \mathrm{~min}$. For serum, tubes without any additives were kept at room temperature and centrifuged at $1,000 \mathrm{~g}$ for $10 \mathrm{~min}$ after coagulation. All samples were stored at $-80^{\circ} \mathrm{C}$.

Gal-3 was determined using a commercially available enzymelinked immune-sorbent assay (ELISA; BG Medicine, Inc., Waltham, Mass., USA). High-sensitivity C-reactive protein (hsCRP) concentrations were analyzed by a particle-enhanced immunoturbidimetric method with the use of a Roche Modular P automated clinical chemistry analyser (Roche Diagnostics, Basel, Switzerland) and reagents of Tina-quant C-reactive protein (latex) assay (Roche Diagnostics). N-terminal probrain natriuretic peptide (NT-proBNP) was determined with a Roche Diagnostics NTproBNP assay on an ElecSys 2010 analyser (Roche Diagnostics). Troponin- $\mathrm{T}(\mathrm{TnT})$ concentrations were also measured on this analyser, with the immunoassay TnT (Roche Diagnostics), using biotinylated monoclonal TnT-specific antibody and a monoclonal TnT-specific antibody labelled with ruthenium forming a sandwich complex. Creatinine levels were measured in serum using a photometric method. eGFR was calculated using the Modification of Diet in Renal Disease (MDRD) study equation. The analysis of TnT, NT-proBNP and hsCRP was limited to group 1, and was not performed at the last CMR exam 1 year after MI.

\section{Statistical Analysis}

The statistical analysis was computed in a commercially available statistical calculation program (IBM SPSS v21, IBM, Armonk, New York, N.Y., USA). Continuous values are presented as median and interquartile range (IQR) and $p$ values, and categorical values as absolute number, percentage and p values. Due to the low number of patients in each group, nonparametric methods were used. The Friedman test was used to compare continuous related samples and the Mann-Whitney $U$ test when the samples were unrelated. Categorical data were compared using the Pearson $\chi^{2}$ test and the Fisher exact test. Correlation between data was examined using the Spearman method. A two-sided $p$ value $<0.05$ was considered significant. However, since a number of statistical calculations were made, and in order to adjust for multiple testing, particular attention should be given to the value $\mathrm{p}<0.01$.

\section{Results}

\section{Baseline Characteristics}

Patient characteristics at baseline (group 1 at 1 year and group 2 at 4.4 years following the index MI) are presented in table 1 . When compared with group 2, patients in group 1 were younger (61 vs. 69 years; $\mathrm{p}<0.01$ ), had fewer smokers ( 45 vs. $65 \%$; $\mathrm{p}=0.05$ ) and a larger proportion were male ( 79 vs. $58 \% ; \mathrm{p}=0.04$ ). In the acutely revascularized STEMI group (group 1), no patient required a new revascularization procedure during the first year following the index MI. In contrast, among the patients with a history of complicated MI (group 2), 17\% were revascularized by PCI and $15 \%$ by CABG during the 4.4 years following the index MI. All patients in group 1 were treated with acetylsalicylic acid compared to $87 \%$ in group
Table 1. Baseline characteristics

\begin{tabular}{|c|c|c|c|}
\hline Characteristic & $\begin{array}{l}\text { Group } 1^{\text {a }} \\
(\mathrm{n}=38)\end{array}$ & $\begin{array}{l}\text { Group 2b } \\
(\mathrm{n}=52)\end{array}$ & $\begin{array}{l}\mathrm{p} \\
\text { value }\end{array}$ \\
\hline Age, years & $61[37.8-84.2]$ & $68.6[53.4-83.8]$ & $<0.01$ \\
\hline Male gender & $30(79)$ & $30(58)$ & 0.04 \\
\hline Heart rate & $63.5[57-68.5]$ & $66.5[59-75]$ & 0.07 \\
\hline Systolic BP, mm Hg & $136[100-172]$ & $129.5[92.5-166.5]$ & 0.28 \\
\hline Diastolic BP, mm Hg & $79[54-104]$ & $77.5[53.5-101.5]$ & 0.16 \\
\hline Creatinine, $\mu \mathrm{mol} / \mathrm{l}$ & $71[47.5-94.5]$ & $75.5[47.5-103.5]$ & 0.03 \\
\hline $\mathrm{eGFR}, \mathrm{ml} / \mathrm{min} / 1.73 \mathrm{~m}^{2}$ & $97[70.5-123.5]$ & $74.5[44.5-104.5]$ & $<0.01$ \\
\hline \multicolumn{4}{|l|}{ Medical history } \\
\hline Hypertension & $8(21)$ & $17(33)$ & 0.22 \\
\hline Hyperlipidemia & $9(24)$ & $13(25)$ & 0.89 \\
\hline Smoking & $17(45)$ & $34(65)$ & 0.05 \\
\hline Atrial fibrillation & $1(3)$ & $8(15)$ & 0.05 \\
\hline Diabetes mellitus & $2(5)$ & $5(10)$ & 0.69 \\
\hline MI after index event & 0 & $5(10)$ & 0.71 \\
\hline $\mathrm{HF}$ & 0 & $2(4)$ & 0.51 \\
\hline Stroke & $1(3)$ & $2(4)$ & 1 \\
\hline PVD & $2(5)$ & $4(8)$ & 1 \\
\hline \multicolumn{4}{|c|}{ Revascularization after index event } \\
\hline CABG & 0 & $8(15)$ & 0.02 \\
\hline PCI after index event & 0 & $9(17)$ & $<0.01$ \\
\hline \multicolumn{4}{|l|}{ Drug therapy } \\
\hline Acetylsalicylic acid & $38(100)$ & $45(87)$ & 0.02 \\
\hline Statin & $37(97)$ & $47(90)$ & 0.40 \\
\hline Beta-blocker & $17(45)$ & $33(64)$ & 0.08 \\
\hline ACE-I/ARB & $27(71)$ & $44(85)$ & 0.12 \\
\hline Diuretic & $5(13)$ & $20(39)$ & $<0.01$ \\
\hline Warfarin & $1(3)$ & $4(8)$ & 0.39 \\
\hline Aldosterone antagonist & $3(8)$ & $1(2)$ & 0.31 \\
\hline
\end{tabular}

Continuous variables are expressed as median [IQR] and categorical variables as $\mathrm{n}(\%)$. ACE- $\mathrm{I}=$ Angiotensin-converting enzyme inhibitor; $\mathrm{ARB}=$ angiotensin receptor blocker; $\mathrm{BP}=$ blood pressure; $\mathrm{CABG}=$ coronary artery bypass grafting; $\mathrm{PVD}=$ peripheral vascular disease.

${ }^{a} 1$ year after MI.

b 4.4 years after MI. $2(\mathrm{p}=0.02)$. Fewer patients in group 1 than group 2 were treated with diuretics: 13 versus $39 \%(\mathrm{p}<0.01)$. Median eGFR was 97 (70.5-123.5) and $74.5(44.5-104.5) \mathrm{ml} /$ $\min / 1.73 \mathrm{~m}^{2}$ in group 1 and group 2 , respectively $(\mathrm{p}<$ 0.01 ). There were no significant differences in CMR findings between the 2 groups, although a trend towards larger MI size $(\mathrm{p}=0.06)$ was observed for group 1 versus group 2 (table 2 ).

\section{Galectin-3 Levels}

The median Gal-3 value of the healthy controls was 10.16 (5.59-14.73) $\mathrm{ng} / \mathrm{ml}$. Compared with the controls, Gal-3 levels were significantly $(\mathrm{p}=0.03)$ higher both in group 1 at 1 year $(11.93,6.34-17.52 \mathrm{ng} / \mathrm{ml})$ and in group 2 at 4.4 years after the index MI $(12.96,6.33-19.29 \mathrm{ng} / \mathrm{ml})$. 


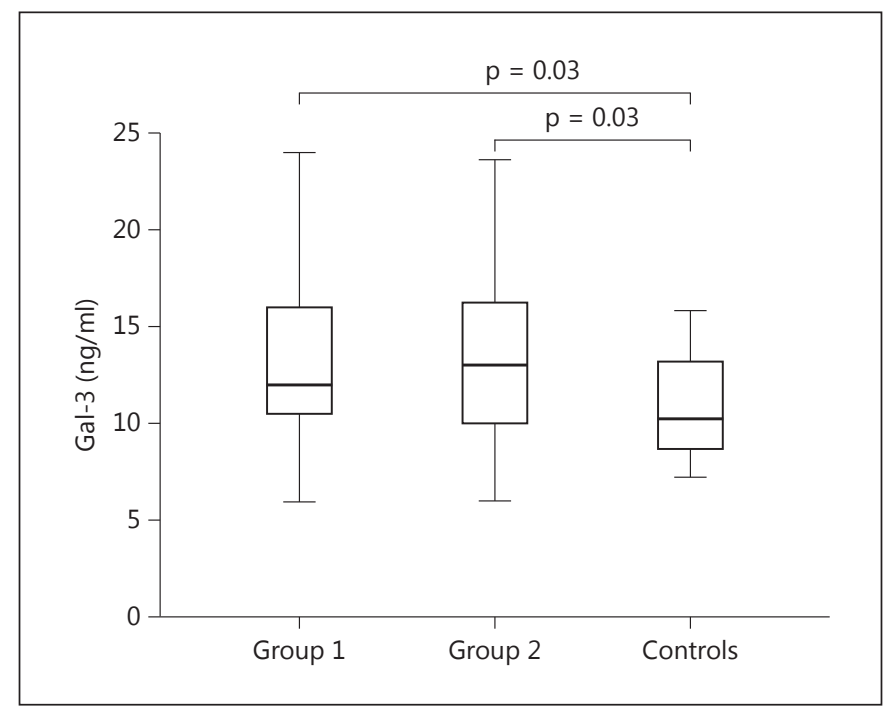

Fig. 1. Gal-3 levels in group 1 (at 1 year following STEMI, $\mathrm{n}=38$ ), group $2(>4$ years after MI, $\mathrm{n}=52)$ and healthy controls $(\mathrm{n}=22)$. Both patient groups had higher Gal-3 levels than the healthy controls, but levels similar to each other. The bottom and the top of the boxes represent the first and the third quartiles, respectively, while the band inside the boxes corresponds to the median value. The whiskers depict the minimum and the maximum value.

Table 2. Findings at the final CMR exam

\begin{tabular}{lllc}
\hline CMR findings & $\begin{array}{l}\text { Group 1 } \\
(\mathrm{n}=38)\end{array}$ & $\begin{array}{l}\text { Group 2 } \\
(\mathrm{n}=52)\end{array}$ & p value \\
\hline LVEDVi, $\mathrm{ml} / \mathrm{m}^{2}$ & $87.5[54.8-120.2]$ & $79.2[37.1-121.3]$ & 0.21 \\
LVESVi, $\mathrm{ml} / \mathrm{m}^{2}$ & $41.8[17.6-66.0]$ & $39.1[9.7-68.5]$ & 0.95 \\
LVEF, \% & $53.5[39.5-67.2]$ & $50.3[30.3-70.3]$ & 0.17 \\
LV mass indexed, g/m & $56.8[44.9-68.7]$ & $76.9[45.6-107.2]$ & $<0.001$ \\
Infarct size, \% LV mass & $14.5[6.5-22.5]$ & $11.7[1.7-21.7]$ & 0.06 \\
\hline
\end{tabular}

Data are presented as median [IQR].

a 1 year after MI.

b 4.4 years after MI.

There was no difference $(\mathrm{p}=0.73)$ in Gal-3 levels between these 2 groups (fig. 1). In group 1,2.8\% of the patients had Gal-3 above the FDA-cleared threshold value $(\geq 17.8 \mathrm{ng} /$ $\mathrm{ml}$ ) before PCI, while $10.5 \%$ had elevated levels at 1 year post-MI. In group 2, $11.5 \%$ of the patients had Gal-3 levels above this limit. The Gal-3 levels did not change significantly during the first year following acute MI (group $1: \mathrm{n}=23$; fig. 2). In both groups, Gal-3 was negatively correlated with eGFR at baseline (group 1: Gal-3 at 1 year, $\mathrm{r}=-0.40, \mathrm{p}=0.01$; Group 2: $\mathrm{r}=-0.63, \mathrm{p}<0.01)$.

Gal-3 Levels and Acute MI in Ischemic Heart Disease

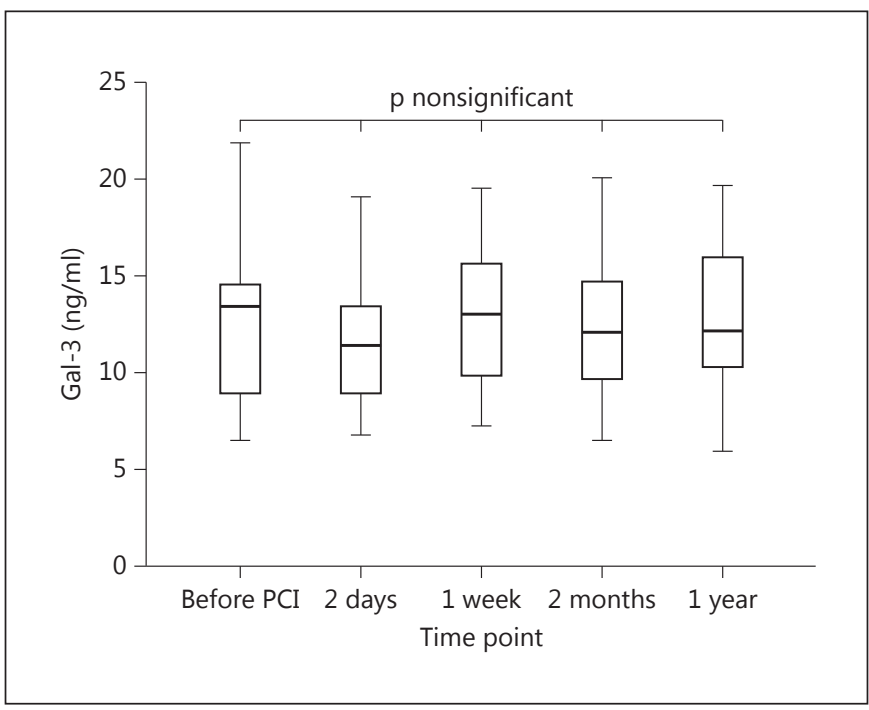

Fig. 2. Gal-3 levels in group $1(n=23)$ at the different time points throughout the first year after acute STEMI. Gal-3 levels were stable and did not change significantly during this period. The bottom and the top of the boxes represent the first and the third quartiles, respectively, while the band inside the boxes corresponds to the median value. The whiskers depict the minimum and the maximum value.

Gal-3, Other Biomarkers and Imaging Parameters

In group 1, the median NT-proBNP measured before PCI was $14.5 \mathrm{pmol} / \mathrm{l}(6.6-23.1)$, at 2 days $157.0 \mathrm{pmol} / \mathrm{l}$ (118.1-305.2), and at 1 week post-PCI $55.6 \mathrm{pmol} / 1$ (32.1-114.6), whereas the median NT-proBNP at 2 months was $32.9 \mathrm{pmol} / \mathrm{l}(21.0-79.3$; $\mathrm{p}<0.01$ for the comparison of all time points). Gal-3 assessed before PCI showed a weak correlation with NT-proBNP at 2 days $(\mathrm{r}=0.45, \mathrm{p}=0.04)$ and 1 week $(\mathrm{r}=0.44, \mathrm{p}=0.05)$, while the strongest association between Gal-3 and NTproBNP was found between Gal-3 at 2 days and NTproBNP at 1 week $(r=0.57, p=0.01)$. Gal-3 levels analyzed at 2 months post-PCI were weakly correlated with NT-proBNP at 2 days $(\mathrm{r}=0.46, \mathrm{p}=0.04)$ and 2 months $(\mathrm{r}=0.44, \mathrm{p}=0.05)$. Gal-3 measured at 1 week and 1 year after PCI was not associated with NT-proBNP measured at any time point.

In group 2, the median NT-proBNP was $236.6 \mathrm{pmol} / 1$ (98.3-491.0). NT-proBNP correlated significantly with Gal-3 $(\mathrm{r}=0.47, \mathrm{p}<0.01)$, LVEDVi $(\mathrm{r}=0.39, \mathrm{p}<0.01)$ and LVESVi $(r=0.34, p=0.01)$, but not with LVEF and MI size. NT-proBNP was significantly higher in group 2 compared to at all time points in group $1(\mathrm{p}<0.01)$, except during the acute course of STEMI ( 2 days post-PCI). 
In group 1, the maximal TnT level during the course of acute MI had a median value of $5.34 \mu \mathrm{g} / \mathrm{l}(2.93-8.55)$. The median hsCRP level before PCI was $3.1 \mathrm{mg} / \mathrm{l}(1.0$ $6.2), 33.0 \mathrm{mg} / \mathrm{l}(14.5-73.0)$ at 2 days post-PCI, $9.8 \mathrm{mg} / \mathrm{l}$ $(2.4-18.4)$ at 1 week and $1.6 \mathrm{mg} / \mathrm{l}(0.8-3.0)$ at 2 months. Gal-3 did not correlate with max TnT or hsCRP at any time point.

\section{Gal-3 and CMR Imaging Parameters}

In group 1, there was a highly significant decrease in infarct size $(\mathrm{p}<0.01)$ and LVESVi $(\mathrm{p}<0.01)$ but not in LVEDVi during the first year following revascularized MI. Surprisingly, there was no significant correlation between Gal-3 levels and MI size, LV volumes or LVEF at 1 year following MI $(\mathrm{n}=38)$. Furthermore, there was no association between Gal-3 concentrations and infarct size, $\mathrm{LV}$ volumes or LVEF at any of the 4 time points during the first year after STEMI $(n=23)$. In contrast, in group 2, Gal-3 levels correlated modestly with infarct size $(\mathrm{r}=0.28, \mathrm{p}<0.05)$, LVEDVi $(\mathrm{r}=0.4, \mathrm{p}<0.01)$, LVESVi $(\mathrm{r}=0.43, \mathrm{p}<0.01)$ and $\operatorname{LVEF}(\mathrm{r}=-0.39, \mathrm{p}<0.01)$.

\section{Discussion}

This study presents novel, important data regarding circulating Gal-3 in ischemic heart disease. There was no relationship between Gal-3 levels and acute myocardial ischemic injury, a finding which is supported by the following results. First, there was no association between Gal-3 and infarct size or LV volumes assessed by CMR. Second, Gal-3 levels did not correlate with TnT, a marker of myocardial damage. Third, circulating Gal-3 did not change when measured at several time points during the course of acute STEMI. In contrast to the acute setting, there was a modest but significant relationship between Gal-3 levels, MI size and LV volumes in patients with old MI.

In the current study, no association was found between Gal-3 and LV volumes or infarct size at any of the 4 time points during the first year following successfully revascularized first-time STEMI. To date, only limited data are available regarding the relationship between Gal3 and cardiac structure and function in both MI and HF populations. Echocardiographic studies in HF have failed to demonstrate an association between Gal-3 and indices of LV size and systolic function $[6,19]$, while Gal-3 was shown to correlate with parameters of diastolic function in a study on dyspneic patients with and without HF [6]. In 2 different STEMI populations, Gal-3 has been shown to correlate negatively with LVEF measured by echocardiography at 30 days post-MI [20], and to be associated with MI size, but not LVEF, estimated by CMR at 4 months after STEMI [21], respectively. In the latter population, when the patients were stratified according to Gal3 level above or below the median concentration of 10.86 $\mathrm{ng} / \mathrm{ml}$, the patients with elevated Gal-3 had a significantly lower LVEF than those with low Gal-3 [21]. Our findings are compatible with the results of Weir et al. [22], who assessed 100 patients with acute MI and LV dysfunction (echocardiographic LVEF $<40 \%$ ) without clinical or radiological signs of $\mathrm{HF}$ at the inclusion. In this population, assessed by CMR at baseline and after 24 weeks, no clear association between Gal-3 and infarct size or LV volumes was found when analyzed across the entire population, although Gal-3 at baseline showed a moderate correlation with LVEF at 24 weeks. On the other hand, in this study, Gal-3 was associated with remodeling in the subgroup of patients with baseline LVEF (at CMR) above the median of $49.2 \%$. In a large, acute STEMI population ( $\mathrm{n}=247$, a GIPS-III substudy) examined by van der Velde et al. [23], patients with elevated Gal-3 ( $\geq 17.8 \mathrm{ng} / \mathrm{ml})$ measured at hospital admission had lower LVEF, higher LV end-systolic volume and larger infarct size evaluated by CMR 4 months after the MI than patients with levels below this limit. Furthermore, baseline Gal-3 did predict LVEF and infarct size at 4 months; interestingly, in agreement with our study, Gal-3 measured at 4 months did not predict these parameters. In our study, no significant relationship between baseline Gal-3 and LV volumes or myocardial damage assessed according to TnT level or by CMR was identified in the patients with acute STEMI. There are important differences between this large population and the patients in our group 1, which could contribute to the divergent results between the 2 studies. All of our group 1 patients had single-vessel CAD with an acute proximal occlusion in the affected artery; this inclusion criterion was imperative for the creation of an experimental model seeking to isolate the myocardial effects of first-time STEMI from the influence of other factors. Among the patients studied by van der Velde et al. [23], 55.9\% had TIMI 0 flow, while the remaining $44.1 \%$ (36\% TIMI 2 or 3 ) had flow in the culprit vessel at coronary angiography. In the original population of the GIPSIII trial, $68.1 \%$ of the patients had single-vessel disease [24]. Furthermore, a smaller proportion of our patients with acute STEMI had Gal-3 levels $\geq 17.8 \mathrm{ng} / \mathrm{ml}, 2.8 \%$ before PCI and $10.5 \%$ at 1 year post-MI, compared to the 16.2 and $16.6 \%$ at baseline and 4 months following MI, respectively, in the study by van der Velde et al. [23]. This 
could indicate differences in the background factors, the complexity of the underlying CAD and the pathological mechanism in the culprit vessel in the 2 populations, which could have implications for the relationship between Gal-3 and LV remodeling and MI size. If an association only exists between Gal-3, MI size and LV remodeling at certain time points after STEMI, it would indicate an intricate interplay between these factors that changes over time following MI.

In this study, we found elevated circulating Gal-3 levels in patients with MI (groups 1 and 2) compared to a healthy reference population (group 3). This is compatible with previous publications $[20,22,25]$. However, in contrast to other studies reporting a modest increase in Gal-3 after MI $[22,23]$, we did not detect any significant changes in serum Gal-3 levels measured repeatedly during the first year following revascularized first-time STEMI. Previously, in a small population, Gal-3 was described as stable compared to baseline when measured 1 year after MI [26]. Considering the available laboratory research, the observation that Gal-3 is stable or increases only modestly after acute MI is unexpected. In rats, a 96-fold increase in Gal3 mRNA expression was found in the infarcted myocardium during acute MI compared to controls [27]. In this model, the myocardial expression of Gal-3 in the infarcted area was reported to peak at 1 week post-MI, and Gal-3 mRNA expression in the remote myocardium was also significantly elevated when compared to rats without MI, but to a lesser degree than in the infarcted myocardium (3- vs. 96-fold) and with a later maximum value, at 6 months post-MI [27]. The relationship between serum Gal-3 levels and tissue levels has not been investigated in clinical studies on MI populations, but no correlation between circulating and myocardial Gal-3 could be demonstrated in hypertensive heart disease [28]. Therefore, a lack of an association between circulating Gal-3 levels, infarct size and LV remodeling may not rule out a role for Gal-3 at a myocardial level. Thereby, when interpreting our data in conjunction with previous publications, a clear picture describing the relationship between circulating Gal-3 levels and acute MI in humans has yet to be drawn.

Infarct size is a major determinant of adverse LV remodeling post-MI $[16,29]$ and, together with parameters of LV remodeling, is an important predictor of adverse CV events [30-32]. Although Gal-3 predicts morbidity and mortality in HF populations, no clear association between LV anatomy and systolic function (evaluated by echocardiography) and Gal-3 has been demonstrated. We utilized CMR, a more powerful tool than echocardiography, and found significant associa-

Gal-3 Levels and Acute MI in Ischemic Heart Disease tions between Gal-3 and MI size and LV volumes in patients with previous, complicated MI. Gal-3 was correlated with NT-proBNP in these patients $(\mathrm{r}=0.47, \mathrm{p}<$ 0.01 ), but the 2 biomarkers did not correlate when measured at the same time point in the patients with acute STEMI. No significant differences in MI size and LV volumes were found between the 2 groups at the CMR exams; nevertheless, NT-proBNP was significantly higher in group 2 than in group 1 when measured after the acute phase of STEMI ( 1 week and 2 months postPCI; $\mathrm{p}<0.01$ ). These findings imply a role for Gal-3 in maladaptive processes in long-term survivors of MI, but stand in contrast to the data in the patients with acute MI. Several factors may have contributed to the differences. Compared to the patients with acute MI, the patients with previous MI were older, had more complicated disease and more time had elapsed since the index event. More elapsed time could indicate an increased fibrotic state, which might implicate higher levels of Gal-3 [33, 34]. Advanced age has previously been linked to higher levels of Gal-3 $[6,10]$. Furthermore, the patients in group 2 had more severe CAD, which might be suggestive of increased low-grade inflammation and fibrosis [35]. Both fibrosis and inflammation have been associated with increased Gal-3 levels [2, 3]. Further clinical studies are warranted to elucidate both the mechanistic role of Gal-3 in the pathophysiology of acute and old MI and HF and its possible utility in patient risk stratification in acute and old MI.

\section{Limitations}

Due to the relatively small sample size of this study, there is a possibility that selection bias and biological heterogeneity may have influenced the results, including our ability to detect a possible relationship between Gal-3 and infarct size or LV remodeling in acute MI. However, the relation between Gal-3 levels and CMR parameters was consistent at all 4 time points. Furthermore, the number of possible confounders, such as prior MI, multivessel disease, differences in revascularization techniques, varying patency in the infarct-related artery prior to and after PCI and various comorbidities that could involve inflammatory mechanisms, are reduced by the rigorous selection criteria of patients in group 1, which collectively counteract this limitation. A further consequence of these rigorous criteria is that the applicability of our results in group 1 are limited to patients with first-time STEMI and single-vessel disease treated with primary PCI. 


\section{Conclusion}

Gal-3 levels are elevated in patients with ischemic heart disease when compared to healthy individuals. In acute MI, we could not demonstrate a relationship between Gal-3 levels and infarct size or LV volumes, and we found no significant change in Gal-3 levels either during the acute phase or in the first year following acute MI. In contrast, Gal-3 levels were modestly correlated with MI size and LV remodeling in patients with old MI. These findings may suggest that circulating Gal-3 levels do not reflect myocardial damage subsequent to acute myocardial ischemia. Further studies, both experimental and clinical, are needed to clarify the role of Gal-3 in the pathophysiology of ischemic heart disease, and the utility of this biomarker in this clinical setting.

\section{Acknowledgements}

BG Medicine Inc. (Waltham, Mass., USA) provided specimen measurement services related to this study. The study was financed by Helse Vest (grant No. 911017), the Norwegian Heart and Lung Patient Association 'Helse og Rehabilitering' (grant No. 2003/2/0211) and the SR-Bank Fund for Public Welfare. Amersham Health, a division of GE Healthcare Ltd., Little Chalfont, UK, supplied the CMR contrast needed to perform the study.

\section{Conflict of Interest}

None declared.

\section{References}

1 Mendis S, Puska P, Norrving B: Global atlas on cardiovascular disease prevention and control. World Health Organization, Geneva, 2011.

-2 de Boer RA, Voors AA, Muntendam P, van Gilst WH, van Veldhuisen DJ: Galectin-3: a novel mediator of heart failure development and progression. Eur J Heart Fail 2009;11: 811-817.

-3 Filipe MD, Meijers WC, Rogier van der Velde A, de Boer RA: Galectin-3 and heart failure: prognosis, prediction and clinical utility. Clin Chim Acta 2015;443:48-56.

-4 Ho JE, Liu C, Lyass A, Courchesne P, Pencina MJ, Vasan RS, Larson MG, Levy D: Galectin-3, a marker of cardiac fibrosis, predicts incident heart failure in the community. J Am Coll Cardiol 2012;60:1249-1256.

$\checkmark 5$ de Boer RA, van Veldhuisen DJ, Gansevoort RT, Muller Kobold AC, van Gilst WH, Hillege HL, Bakker SJ, van der Harst P: The fibrosis marker galectin-3 and outcome in the general population. J Intern Med 2012;272:55-64.

-6 Shah RV, Chen-Tournoux AA, Picard MH, van Kimmenade RR, Januzzi JL: Galectin-3, cardiac structure and function, and long-term mortality in patients with acutely decompensated heart failure. Eur J Heart Fail 2010;12: 826-832.

7 de Boer RA, Lok DJ, Jaarsma T, van der Meer P, Voors AA, Hillege HL, van Veldhuisen DJ: Predictive value of plasma galectin-3 levels in heart failure with reduced and preserved ejection fraction. Ann Med 2011;43:60-68.

8 de Boer RA, Edelmann F, Cohen-Solal A, Mamas MA, Maisel A, Pieske B: Galectin-3 in heart failure with preserved ejection fraction. Eur J Heart Fail 2013;15:1095-1101.

-9 Carrasco-Sanchez FJ, Aramburu-Bodas O, Salamanca-Bautista P, Morales-Rull JL, Ga-
listeo-Almeda L, Paez-Rubio MI, AriasJimenez JL, Aguayo-Canela M, Perez-Calvo JI: Predictive value of serum galectin-3 levels in patients with acute heart failure with preserved ejection fraction. Int J Cardiol 2013; 169:177-182.

10 Gullestad L, Ueland T, Kjekshus J, Nymo SH, Hulthe J, Muntendam P, Adourian A, Bohm M, van Veldhuisen DJ, Komajda M, Cleland JG, Wikstrand J, McMurray JJ, Aukrust P, Group CS: Galectin-3 predicts response to statin therapy in the controlled rosuvastatin multinational trial in heart failure (corona). Eur Heart J 2012;33:2290-2296.

11 Anand IS, Rector TS, Kuskowski M, Adourian $\mathrm{A}$, Muntendam $\mathrm{P}$, Cohn JN: Baseline and serial measurements of galectin-3 in patients with heart failure: relationship to prognosis and effect of treatment with valsartan in the Val-HeFT. Eur J Heart Fail 2013;15:511-518.

12 Yancy CW, Jessup M, Bozkurt B, Butler J, Casey DE Jr, Drazner MH, Fonarow GC, Geraci SA, Horwich T, Januzzi JL, Johnson MR, Kasper EK, Levy WC, Masoudi FA, McBride PE, McMurray JJ, Mitchell JE, Peterson PN, Riegel B, Sam F, Stevenson Writing Committee Members, Yancy CW, Jessup M, Bozkurt B, et al: 2013 ACCF/AHA guideline for the management of heart failure: a report of the American College of Cardiology Foundation/ American Heart Association Task Force on practice guidelines. Circulation 2013;128: 240-327.

13 McMurray JJ, Adamopoulos S, Anker SD, Auricchio A, Bohm M, Dickstein K, Falk V, Filippatos G, Fonseca C, Gomez-Sanchez MA, Jaarsma T, Kober L, Lip GY, Maggioni AP, Parkhomenko A, Pieske BM, Popescu BA, Ronnevik PK, Rutten FH, Schwitter J, Se- ferovic P, Stepinska J, Trindade PT, Voors AA, Zannad F, Zeiher A; ESC Committee for Practice Guidelines: Esc guidelines for the diagnosis and treatment of acute and chronic heart failure 2012: the Task Force for the Diagnosis and Treatment of Acute and Chronic Heart Failure 2012 of the European Society of Cardiology. Developed in collaboration with the Heart Failure Association (HFA) of the ESC. Eur Heart J 2012;33:1787-1847.

14 Maiolino G, Rossitto G, Pedon L, Cesari M, Frigo AC, Azzolini M, Plebani M, Rossi GP: Galectin-3 predicts long-term cardiovascular death in high-risk patients with coronary artery disease. Arterioscler Thromb Vasc Biol 2015;35:725-732.

15 Manhenke C, Orn S, von Haehling S, Wollert KC, Ueland T, Aukrust P, Voors AA, Squire I, Zannad F, Anker SD, Dickstein K: Clustering of 37 circulating biomarkers by exploratory factor analysis in patients following complicated acute myocardial infarction. Int $\mathrm{J}$ Cardiol 2013;166:729-735.

16 Sutton MG, Sharpe N: Left ventricular remodeling after myocardial infarction: pathophysiology and therapy. Circulation 2000; 101:2981-2988.

-17 Meijers WC, van der Velde AR, Pascual-Figal DA, de Boer RA: Galectin-3 and post-myocardial infarction cardiac remodeling. Eur J Pharmacol 2015;763:115-121.

18 Dickstein K, Kjekshus J; OPTIMAAL Steering Committee of the OPTIMAAL Study Group: Effects of losartan and captopril on mortality and morbidity in high-risk patients after acute myocardial infarction: the OPTIMAAL randomised trial. Optimal Trial in Myocardial Infarction with Angiotensin II Antagonist Losartan. Lancet 2002;360:752760. 
19 Liu YH, D’Ambrosio M, Liao TD, Peng H, Rhaleb NE, Sharma U, Andre S, Gabius HJ, Carretero OA: N-acetyl-seryl-aspartyl-lysylproline prevents cardiac remodeling and dysfunction induced by galectin-3, a mammalian adhesion/growth-regulatory lectin. Am J Physiol Heart Circ Physiol 2009;296:H404H412.

20 Tsai TH, Sung PH, Chang LT, Sun CK, Yeh $\mathrm{KH}$, Chung SY, Chua S, Chen YL, Wu CJ, Chang HW, Ko SF, Yip HK: Value and level of galectin-3 in acute myocardial infarction patients undergoing primary percutaneous coronary intervention. J Atheroscler Thromb 2012;19:1073-1082.

-21 Mayr A, Klug G, Mair J, Streil K, Harrasser B, Feistritzer HJ, Jaschke W, Schocke M, Pachinger $\mathrm{O}$, Metzler B: Galectin-3: relation to infarct scar and left ventricular function after myocardial infarction. Int J Cardiol 2013;163: 335-337.

-22 Weir RA, Petrie CJ, Murphy CA, Clements S, Steedman T, Miller AM, McInnes IB, Squire IB, Ng LL, Dargie HJ, McMurray JJ: Galectin-3 and cardiac function in survivors of acute myocardial infarction. Circ Heart Fail 2013;6:492-498.

-23 van der Velde AR, Lexis CP, Meijers WC, van der Horst IC, Lipsic E, Dokter MM, van Veldhuisen DJ, van der Harst P, de Boer RA: Galectin-3 and sST2 in prediction of left ventricular ejection fraction after myocardial infarction. Clin Chim Acta 2016;452:50-57.

24 Lexis CP, van der Horst IC, Lipsic E, Wieringa WG, de Boer RA, van den Heuvel AF, van der Werf HW, Schurer RA, Pundziute G, Tan ES, Nieuwland W, Willemsen HM, Dorhout B, Molmans BH, van der HorstSchrivers AN, Wolffenbuttel BH, ter Horst
GJ, van Rossum AC, Tijssen JG, Hillege HL, de Smet BJ, van der Harst P, van Veldhuisen DJ; GIPS-III Investigators: Effect of metformin on left ventricular function after acute myocardial infarction in patients without diabetes: the GIPS-III randomized clinical trial. JAMA 2014;311:1526-1535.

25 Alturfan AA, Basar I, Emekli-Alturfan E, Ayan F, Koldas L, Emekli N: Galectin-3 and plasma cytokines in patients with acute myocardial infarction. Lab Med 2014;45: 336-341.

26 Kruk M, Menon V, Kadziela J, Sadowski Z, Ruzyllo W, Janas J, Roik M, Opolski G, Zmudka K, Czunko P, Kurowski M, Busz-Papiez B, Zinka E, Jablonski W, Jaworska K, Raczynska A, Skonieczny G, Forman S, Li D, Hochman J: Impact of percutaneous coronary intervention on biomarker levels in patients in the subacute phase following myocardial infarction: the Occluded Artery Trial (OAT) biomarker ancillary study. BMC Cardiovasc Disord 2013;13:91.

27 Sanchez-Mas J, Lax A, Asensio-Lopez MC, Fernandez-Del Palacio MJ, Caballero L, Garrido IP, Pastor F, Januzzi JL, Pascual-Figal DA: Galectin-3 expression in cardiac remodeling after myocardial infarction. Int J Cardiol 2014;172:e98-e101.

28 Lopez B, Gonzalez A, Querejeta R, Zubillaga E, Larman M, Diez J: Galectin-3 and histological, molecular and biochemical aspects of myocardial fibrosis in heart failure of hypertensive origin. Eur J Heart Fail 2015;17:385392.

29 Orn S, Manhenke C, Anand IS, Squire I, Nagel E, Edvardsen T, Dickstein K: Effect of left ventricular scar size, location, and transmurality on left ventricular remodeling with healed myocardial infarction. Am J Cardiol 2007;99: 1109-1114.

30 Wu E, Ortiz JT, Tejedor P, Lee DC, Bucciarelli-Ducci C, Kansal P, Carr JC, Holly TA, Lloyd-Jones D, Klocke FJ, Bonow RO: Infarct size by contrast enhanced cardiac magnetic resonance is a stronger predictor of outcomes than left ventricular ejection fraction or endsystolic volume index: prospective cohort study. Heart 2008;94:730-736.

- 31 Bolognese L, Neskovic AN, Parodi G, Cerisano G, Buonamici P, Santoro GM, Antoniucci D: Left ventricular remodeling after primary coronary angioplasty: patterns of left ventricular dilation and long-term prognostic implications. Circulation 2002; 106:23512357.

32 White HD, Norris RM, Brown MA, Brandt PW, Whitlock RM, Wild CJ: Left ventricular end-systolic volume as the major determinant of survival after recovery from myocardial infarction. Circulation 1987;76:44-51.

- 33 Orn S, Manhenke C, Squire IB, Ng L, Anand I, Dickstein K: Plasma MMP-2, MMP-9 and $\mathrm{N}$-BNP in long-term survivors following complicated myocardial infarction: relation to cardiac magnetic resonance imaging measures of left ventricular structure and function. J Card Fail 2007;13:843-849.

34 Manhenke C, Ueland T, Jugdutt BI, Godang K, Aukrust P, Dickstein K, Orn S: The relationship between markers of extracellular cardiac matrix turnover: infarct healing and left ventricular remodelling following primary PCI in patients with first-time STEMI. Eur Heart J 2014;35:395-402.

35 Hansson GK: Inflammation, atherosclerosis, and coronary artery disease. N Engl J Med 2005;352:1685-1695. 